\title{
Does Sclerostin Depletion Stimulate Fracture Healing in a Mouse Model?
}

\author{
Mohammad M. Alzahrani MD, MSc, Frank Rauch MD, \\ Reggie C. Hamdy MB, MSc(Ortho), FRCS(C)
}

Received: 6 August 2015/Accepted: 13 November 2015/Published online: 25 November 2015

(C) The Association of Bone and Joint Surgeons (B) 2015

\begin{abstract}
Background Sclerostin is a secreted glycoprotein that inhibits the intracellular Wnt signaling pathway, which, when inactivated, stimulates bone formation. This has been seen in fracture studies, which have shown larger and stronger calluses with accelerated fracture healing in sclerostin knockout and sclerostin antibody injection
\end{abstract}

Each author certifies that he or she, or a member of his or her immediate family, has no funding or commercial associations (eg, consultancies, stock ownership, equity interest, patent/licensing arrangements, etc) that might pose a conflict of interest in connection with the submitted article.

All ICMJE Conflict of Interest Forms for authors and Clinical Orthopaedics and Related Research ${ }^{\circledR}$ editors and board members are on file with the publication and can be viewed on request.

Clinical Orthopaedics and Related Research ${ }^{\mathbb{R}}$ neither advocates nor endorses the use of any treatment, drug, or device. Readers are encouraged to always seek additional information, including FDAapproval status, of any drug or device prior to clinical use.

Each author certifies that his or her institution approved the animal protocol for this investigation and that all investigations were conducted in conformity with ethical principles of research.

This work was performed at Shriners Hospital for Children, Montreal Children's Hospital, Montreal, Quebec, Canada.

Electronic supplementary material The online version of this article (doi:10.1007/s11999-015-4640-z) contains supplementary material, which is available to authorized users.

M. M. Alzahrani, F. Rauch, R. C. Hamdy

Shriners Hospital for Children, Montreal Children's Hospital,

Montreal, QC, Canada

M. M. Alzahrani, R. C. Hamdy

Division of Orthopaedic Surgery, McGill University, Montreal,

QC, Canada

M. M. Alzahrani

Department of Orthopaedic Surgery, University of Dammam,

Dammam, Saudi Arabia models. However, the effects of these two mechanisms have not been compared in the context of fracture healing. Questions/purposes We sought to determine the degree to which sclerostin inhibition (Scl-Ab injection) and complete sclerostin depletion inhibit fracture healing in a mouse model as evaluated by (1) morphometric trabecular bone measures at the fracture site, and (2) fracture site structural strength.

Methods Ten-week-old male sclerostin knockout $(\mathrm{n}=20)$ and wild type $(\mathrm{n}=40)$ mice underwent insertion of a tibial intramedullary pin after which a midshaft tibial osteotomy was performed. The mice were divided in three groups: sclerostin knockout $(n=20)$, wild type with sclerostin antibody injection (intravenous dose of $100 \mathrm{mg} / \mathrm{kg}$ weekly) $(\mathrm{n}=20)$, and wild type with saline injection $(\mathrm{n}=20)$. The mice for each group where subdivided and euthanized at $14,21,28$, and 35 days after surgery, at which time the fractured tibias were assessed with microCT (to assess morphometric trabecular bone measures: bone volume to total volume (BV/TV), trabecular thickness, trabecular number, and structural model index at the fracture site. Biomechanical testing in the form of three-point bending also was done to assess fracture site structural strength. A difference greater than $3.7 \%$ in our primary outcome $(\mathrm{BV} /$

M. M. Alzahrani ( $\square)$

1529 Cedar Avenue, Montreal, QC H3G 1A6, Canada

e-mail: mohammad.alzahrani2@mail.mcgill.ca 
TV) would be required to detect a difference between groups with a power of $80 \%$, as per our power analysis.

Results The wild type with sclerostin antibody and the sclerostin knockout groups showed increased trabecular $\mathrm{BV} / \mathrm{TV}$ at the fracture site compared with the wild type group with saline at all times, however no difference was seen between the treatment groups with the numbers available, except at 28 days postoperatively when the sclerostin knockout group showed greater BV/TV than the wild type sclerostin antibody group $(47.0 \pm 3.5$ vs $40.1 \pm$ $2.1 ; \mathrm{p}<0.05)$. On biomechanical testing the wild type sclerostin antibody showed increased stiffness at Days 14 and 28 compared with the wild type with saline group (70.9 \pm 6.4 vs $14.8 \pm 8.1 ; \mathrm{p}=0.001),(106.8 \pm 24.3$ vs $74.9 \pm$ $16.0 ; \mathrm{p}=0.004)$; respectively. However, with the numbers available, no differences were detected between the wild type with sclerostin antibody and the sclerostin knockout groups in terms of whole-bone structural strength.

Conclusions Sclerostin antibody injections showed promising results, which were not different with the numbers available, from results achieved with complete depletion of sclerostin, especially at earlier stages of the healing process, and therefore completed the healing process at an earlier time.

Clinical Relevance Sclerostin antibody injections appear to enhance fracture healing to a degree that is not different than complete sclerostin depletion, but larger animal studies are required to assess the accurate dosage and timing of administration in the fracture healing process to further evaluate its potential clinical utility to enhance fracture healing.

\section{Introduction}

Long-bone fractures are common, and depending on the pattern of injury, they can be difficult to treat thus leading to increased risk of delayed union or nonunion [1]. Current management options for nonunions include bone grafting, growth factor implantation, and stem cell therapy, but they do not consistently succeed and sometimes are associated with complications [1, 24]. These shortcomings justify ongoing research that seeks to improve and augment fracture healing through noninvasive approaches.

The process of fracture healing involves multiple pathways, including the $\mathrm{Wnt} / \beta$-catenin and BMP pathways [17]. Currently, multiple therapies seek to enhance the fracture-healing process, one of which is administration of BMPs, which have been shown in randomized controlled trials to be as efficient as autologous bone grafts in the augmentation of tibial fracture healing [10]. However, the high cost of this option, in addition to the high dose required to effectively enhance fracture healing, has led physicians to be cautious with BMP administration [9].
Attention has been directed toward the $\mathrm{Wnt} / \beta$-catenin pathway and its critical role in fracture healing. The Wnt signaling pathway has been described as being a canonical or noncanonical pathway. The canonical pathway is an osteogenic pathway, while the noncanonical pathway does not have an osteogenic effect $[4,7,11]$. The canonical Wnt signaling is initiated by direct binding of the seven-transmembrane looped frizzled proteins and the low-density lipoprotein receptor-related protein 5 and 6 coreceptors after an interaction with specific pathway ligands. This binding leads to the stabilization of $\beta$-catenin, which then translocates to the nucleus and initiates transcription of osteogenic genes thus regulating osteoblast and chondrocyte differentiation [11]. In the Wnt pathway, a glycoprotein called sclerostin is considered a negative regulator of bone formation through binding of lipoprotein receptor-related protein 5 , thus antagonizing the Wnt pathway and downregulating $\beta$-catenin [26]. This effect was first discovered after the description of sclerosteosis. Sclerosteosis is a rare, autosomal-recessive disease causing high bone mass in affected humans; thickened bone and a hyperostotic bony skeleton characterize these patients, which is caused by a mutation in the sclerostin gene (SOST), leading to sclerostin depletion $[2,28]$. This finding has led researchers to study the effect of sclerostin depletion on the osteogenic process in animal and human models $[15,16,22]$. In the genetically altered mouse model in which sclerostin was completely knocked out, it was found that their bones have greater mass and strength owing to increased bone formation [15]. These studies guided researchers to deplete sclerostin through administration of sclerostin antibodies. Two animal studies have shown that sclerostin depletion through systemic administration of sclerostin monoclonal antibody (Scl-Ab) increased bone formation, bone mass, and bone strength in both fracture healing models $[16,22]$.

Although the effect of these two methods on fracture healing has been studied, we could not find a study that compared the efficacy of Scl-Ab administration with complete sclerostin knockout (SOST KO) in the animal model. Fracture healing has been reported to be improved with the Scl-Ab, but the degree of sclerostin depletion with this modality has yet to be determined [6]. We believe that exploring the amount of sclerostin depletion gained with the antibody injections would help direct future research in accurate dosage and timing of injections during the fracture healing process. We therefore sought to compare the effectiveness of Scl-Ab with complete SOST KO in the mouse tibial fracture model at different times of fracture healing, using radiographic and biomechanical endpoints. We sought to determine the degree to which sclerostin inhibition (Scl-Ab injection) and complete sclerostin depletion inhibit fracture healing in a mouse model as 
evaluated by (1) morphometric trabecular bone measures at the fracture site; and (2) fracture site structural strength.

\section{Materials and Methods}

\section{Animal Model of Tibial Fracture}

The McGill Animal Care and Use Committee approved all surgical protocols. The experimental design used 20 SOST KO male mice [13] and 40 male C57BL/6J mice (all from Charles River Laboratories, Montreal, Quebec, Canada). The SOST KO mice were of the same genotype used in a previous study [20]. All the mice had surgery when they were 8 to 10 weeks old and weighed an average of $27 \mathrm{~g}$ (range, 23.2-29.6 g). The C57BL/6J mice were randomly assigned to receive injections of normal saline or Scl-Ab. The SOST KO mice also received normal saline injections. The SOST KO, saline, and Scl-Ab groups were each equally subdivided in four groups according to time of euthanasia (14, 21, 28, and 35 days postosteotomy), with five mice per time. The Scl-Ab (Novartis Pharma AG, Basel, Switzerland) was used for the Sc1-Ab injection group and each mouse received $100 \mathrm{mg} / \mathrm{kg}$ intravenous injections weekly starting 1 week postfracture until euthanasia. This dose was chosen based on a previous study [12]. The dose for the SOST and saline group and the SOST KO group was $0.1 \mathrm{~mL}$ via intravenous injection.

The day of surgery was the first time in the protocol (Day 0 ), and the times of testing were Days 14, 21, 28, and 35 after surgery. For each time, the five mice per group were analyzed by microCT $(\mu \mathrm{CT})$ and biomechanical testing.

\section{Tibial Shaft Fracture Surgery}

All animals underwent a standardized, unilateral tibial shaft fracture, adapted from that described by Bonnarens and Einhorn [3], with intramedullary fixation. Thirty minutes before fracture surgery mice were injected with buprenorphine $(0.1 \mathrm{mg} / \mathrm{kg})$ subcutaneously. The surgery was performed with the animals receiving general anesthesia with $2.5 \%$ to $3 \%$ isoflurane and a $1-\mathrm{L}$ flow rate of oxygen. Prophylactic eye ointment was applied to all mice and 0.2 to $0.5 \mathrm{~mL} / 10 \mathrm{~g}$ body weight of $0.9 \%$ saline was injected subcutaneously. The right leg then was shaved and prepped with $2 \%$ chlorhexidine solution and $70 \%$ ethanol. A 3-mm vertical incision in the skin over the kneecap using the \#11 scalpel blade was made. Blunt dissection then was performed until $1 / 2$ of the tibia was seen. Then using the \#11 scalpel blade, a vertical medial parapatellar incision (approximately $1-1.5 \mathrm{~mm}$ in length) was made. Through this incision, a 26-gauge needle was inserted vertically through the tibial plateau up to the intramedullary canal, then through this needle, a 25-gauge spinal needle was inserted in the canal. The 26-gauge needle was removed and the spinal needle cut at the level of the tibial plateau and bent away from the patellar tendon. The patellar tendon incision then was sutured. Our attention then was directed to performing the fracture at the level of the midtibia. We started blunt dissection through the soft tissue until bone was reached. Then with the use of the microscissors, we gently applied gradual pressure on the tibia until a fracture was induced while keeping the fibula intact. This produced a clean transverse fracture. The dissected soft tissue over the fracture site then was approximated and closed. Before skin closure two to three drops of the lidocaine $1 \%$ /bupivacaine $0.5 \%$ mixture was administered to the open incision. Skin was sutured using monofilament absorbable sutures. During the postoperative period two additional doses of buprenorphine $(0.1 \mathrm{mg} / \mathrm{kg})$ were administered subcutaneously at 24 hours and 48 hours after surgery. Animals were monitored for general postsurgical health and function of the fractured limb. All mice were weighed weekly.

A $\mathrm{CO}_{2}$ overdose was used for euthanasia for all mice. The fractured tibias were dissected and collected. In addition the intramedullary needle was removed carefully from the fractured tibia. The samples were immersed in phosphate-buffered saline and kept frozen until evaluation.

\section{$\mu \mathrm{CT}$ Examination}

Five tibiae per group and time were used for $\mu \mathrm{CT}$ examination. A Skyscan 1172 scanner (Aartselaar, Belgium) was used for this analysis. The area of the fracture (midshaft tibia) was scanned at $72 \mathrm{KV} / 136 \mu \mathrm{A}$ with an $8-\mu \mathrm{m}$ pixel size and a threshold of $0.25 \mathrm{~g} / \mathrm{cm}^{3}$ calcium hydroxyapatite. Image reconstruction was performed using NRecon (Version 1.6.2.0; SkyScan). The CT analyzer (1.11.8.0; SkyScan) was used to measure static histomorphometric parameters of the region of the fractured tibia. The following parameters were determined: bone volume per tissue volume (BV/TV), trabecular thickness, trabecular number, and the structural model index. These parameters were analyzed in the region of interest, which was defined as the callus region with the native cortical bone and marrow space excluded (the region of interest was uniform in all times).

\section{Biomechanical Testing}

The same tibiae used for $\mu \mathrm{CT}$ examination were used to assess the biomechanical properties of the fracture site. A three-point bending test was performed using an Instron ${ }^{\circledR}$ 
5943 microtester (Instron ${ }^{\circledR}$, Norwood, MA, USA). This type of test was chosen based on previous studies [5, 18]. The distance between the supports with the bending fixture was $7 \mathrm{~mm}$ and the diameter of the supports and loading nose was $0.25 \mathrm{~mm}$. A downward bending load was applied to the shaft of the posterior aspect of the fractured tibia (with the loading nose directly over the fracture site) at a rate of $50 \mathrm{~mm} / \mathrm{second}$ until failure. A load-displacement curve was generated using Bluehill 3 software (Instron ${ }^{\circledR}$ ); this was used to determine four parameters: stiffness (N/ $\mathrm{mm})$, ultimate force $(\mathrm{N})$, ultimate displacement $(\mathrm{mm})$, and work to failure $\left(\mathrm{N}^{*} \mathrm{~mm}\right)$.

Principles of laboratory animal care were followed [27]. All 60 mice tolerated the procedure well with adequate weight gain after surgery. None of the mice operated on initially was excluded from the statistical analysis. Postoperative weightbearing was initiated immediately after recovery from anesthesia and until the mice's euthanasia according to the timeline.

\section{Statistical Analysis}

Data were analyzed using SPSS Version 20 (IBM Corp, Armonk, NY, USA). Means and SDs were used for descriptive statistics. Our data (including all variables at all times) was normally distributed (by the Shapiro-Wilk test) and displaced homogeneity of variances (the Levene's test). One-way ANOVA was performed followed by Tukey's post hoc test for data analysis. A probability less than 0.05 was considered statistically significant. A difference greater than $3.7 \%$ in our primary outcome (BV/TV) would be required to detect a difference between groups with a power of $80 \%$, as per our power analysis.

\section{Results}

\section{Trabecular Bone Morphology}

The Scl-Ab and SOST KO groups showed increased trabecular BV/TV compared with the saline group, but they did not differ from one another, with the numbers available, the majority of times (Table 1). The exception was 28 days after surgery, where BV/TV was greater in the SOST KO group than in the Scl-Ab group, $(47.0 \pm 3.5$ vs $40.1 \pm 2.1 ; \mathrm{p}<0.05$ ) (Fig. 1A) (Supplemental Table 1. Supplemental materials are available with the online version of $\mathrm{CORR}^{\circledR}$.). At 21 days trabecular thickness also was increased in the Scl-Ab and SOST KO groups compared with the saline group, but again showed no difference between them with the numbers available

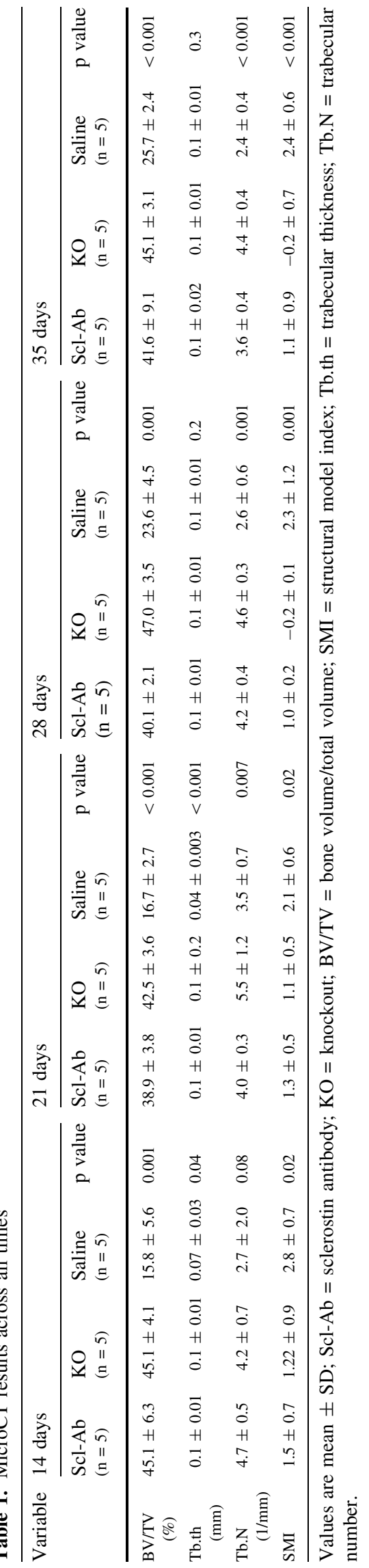


Saline $\square$ KO $\square$ Scl-Ab

$\mathrm{BV} / \mathrm{TV}$
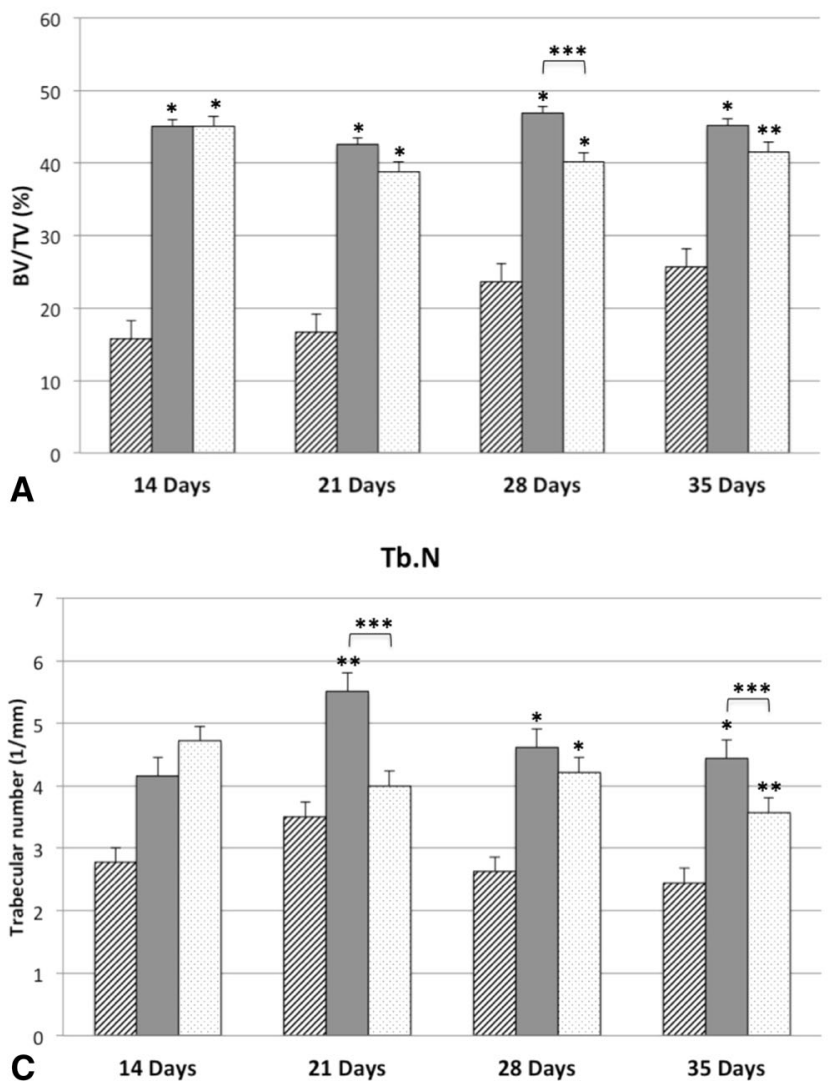

Tb.Th

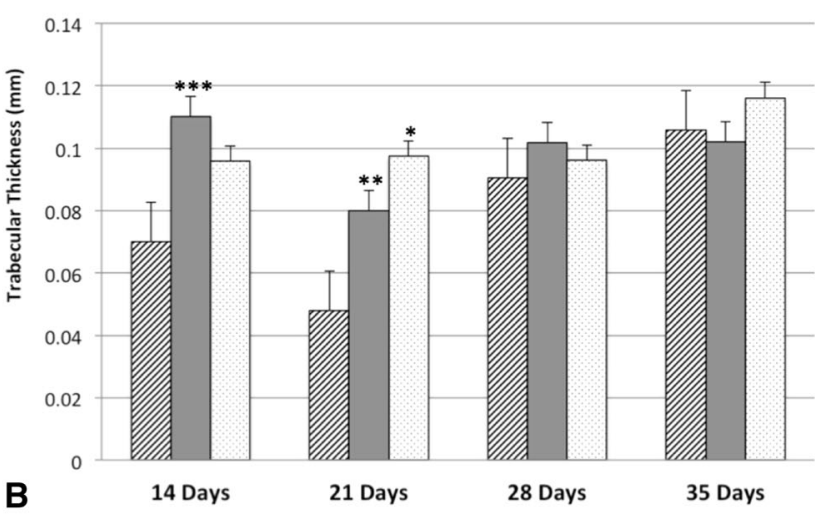

SMI

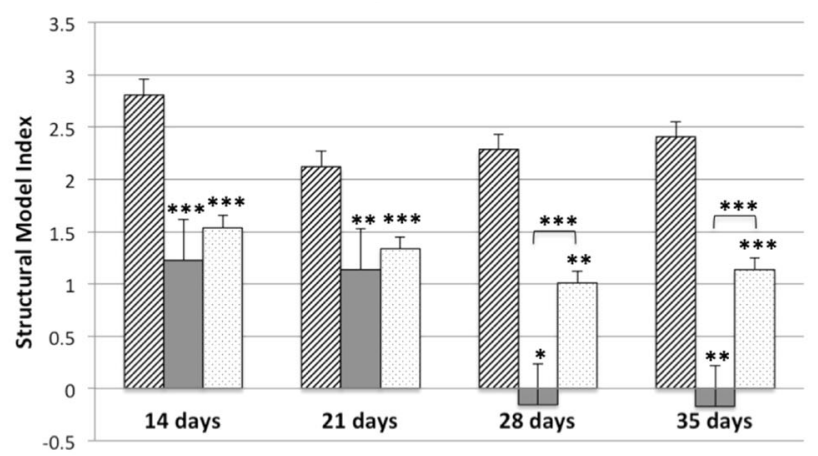

D

Fig. 1A-D (A) Bone volume to total volume (BV/TV) (B) trabecular thickness (Tb.Th), (C) trabecular number (Tb.N), and (D) structural model index (SMI) results are shown. All data are presented as mean, standard error and p value $(* \mathrm{p}<0.001, * * \mathrm{p}<0.01, * * * \mathrm{p}<0.05)$.

(Fig. 1B). These findings also were apparent in trabecular number but at 14 and 21 days after surgery (Fig. 1C). The structural model index was smaller at all times for the Scl$\mathrm{Ab}$ and SOST KO groups compared with the saline group, once more with no difference between the active treatment groups at Days 14 and 21 with the numbers available (Fig. 1D).

\section{Fracture Site Structural Strength}

The Scl-Ab and SOST KO groups showed increased fracture site structural stiffness compared with the saline group at Days 14 and 28, whereas there was no difference between the treatment groups with the numbers available at these times (Table 2). At Day 21 there was no difference in the callus stiffness between the Scl-Ab and the saline groups with the numbers available; in addition, at this time, the SOST KO group showed greater stiffness than the Scl$\mathrm{Ab}$ group $(128.7 \pm 29.4$ vs $86.2 \pm 28.9 ; \mathrm{p}<0.05)$ (Fig. 2A). The SOST KO group showed an increase in the ultimate force and work to failure required compared with the Scl-Ab and saline groups at 21, 28, and 35 days. In addition, with the numbers available, no difference was detected between the Scl-Ab and saline groups with respect to ultimate force required to fracture the callus at all times (Fig. 2B). There were no differences between the groups, with the numbers available, in ultimate displacement throughout the times (Fig. 2C). However, the SOST KO group showed increased work to failure compared with the $\mathrm{Scl}-\mathrm{Ab}$ and saline groups at 21 and 35 days, but with the numbers available, no difference was detected between the SOST KO and Scl-Ab groups at 28 days (Fig. 2D).

\section{Discussion}

The proportion of adult patients who experience nonunions after tibial shaft fractures varies between $2 \%$ and $10 \%$ [19, $23]$, therefore it is imperative that we explore various promising biologically based, less-invasive approaches that might help to improve fracture healing. Sclerostin plays an important role as a negative regulator of the bone formation process, and so may be a potentially viable avenue of 


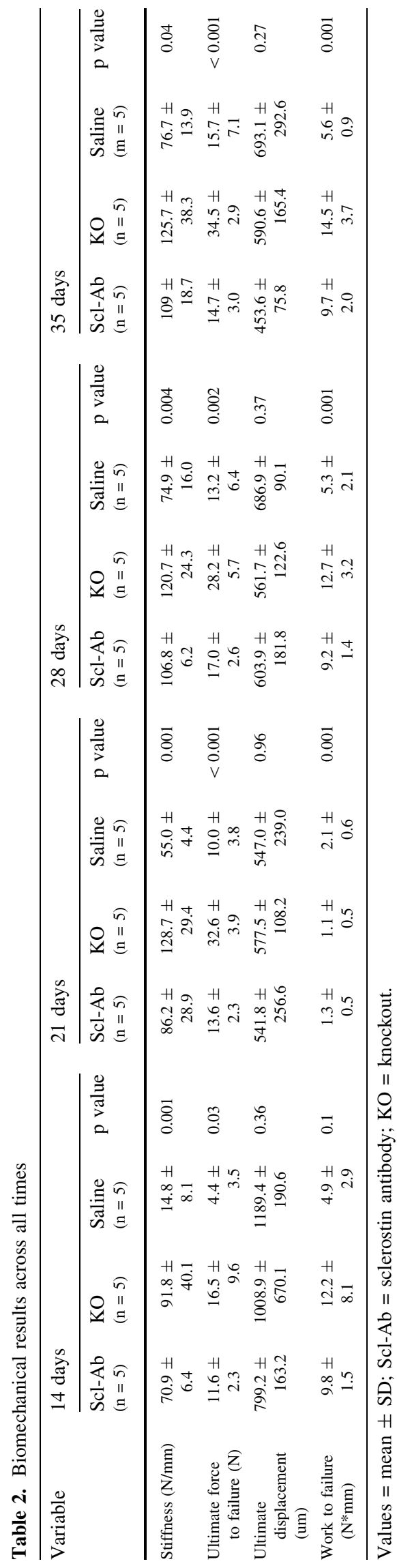

inquiry; in addition, the SOST gene helps govern the quality of bone throughout the skeleton [8]. One study showed that levels of sclerostin were elevated in the serum and locally in the fracture site during the process of fracture healing, acting as a negative regulator in the bone healing pathway [25]. Earlier studies explored sclerostin depletion in two ways: pharmaceutical inhibition through administration of Scl-Ab or genetic depletion by studying SOST KO models $[15,16,22]$, but those studies did not compare the effect of systemic depletion and complete knockout of sclerostin in the same fracture model. Exploring this entity to identify the amount of depletion gained with the sclerostin antibody would help direct future research of dosage and timing of injections. We therefore examined the effect of pharmaceutical and genetic sclerostin depletion on fracture healing in a mouse model. We found that the Scl-Ab and SOST KO groups showed increased trabecular BV/TV at the fracture site compared with the saline group at all times, but showed no difference between the treatment groups with the numbers available (except at 28 days postoperatively, where the SOST KO group showed greater BV/TV than the Scl-Ab group). On biomechanical testing, the Scl-Ab and SOST KO groups showed increased strength in stiffness at Days 14 and 28 compared with the saline group, but again, with the numbers available, no differences were detected between the Scl-Ab and SOST KO groups in terms of whole-bone structural strength.

Limitations of our study include the sample size per group as this may have led to underestimation of some of the findings; to overcome this we performed a power analysis concentrating on our primary outcome (BV/TV) to detect a difference greater than $3.7 \%$ between groups with a power of $80 \%$. Concerning the $\mu \mathrm{CT}$ evaluation of morphologic features of trabecular bone, we did not include volumetric parameters of the formed callus, as our outcomes concentrated more on density-type parameters (including $\mathrm{BV} / \mathrm{TV}$, trabecular thickness, and trabecular number). A minor confounding factor may be the small intramedullary canal of the SOST KO mice compared with wild types, which may have an increased effect on the stability on fixation of the SOST KO group, as mentioned by Morse et al. [21]. In addition, the morphologic structure of bone of the SOST KO mice is different from that of wild-type mice in trabecular bone and strength, which may have an effect on the morphologic results of the study [15].

Genetic depletion of sclerostin has been shown to enhance bone mineral density and fracture healing in the SOST KO mouse model. Li et al. [15] reported increased bone mineral density and bone volume throughout the bony skeleton of the SOST KO mouse model compared with wild type mice. $\mathrm{Li}$ et al. [14] also studied fracture healing in the same model and found that the SOST KO 
Saline $\square$ KO $\square$ Scl-Ab

\section{Stiffness}

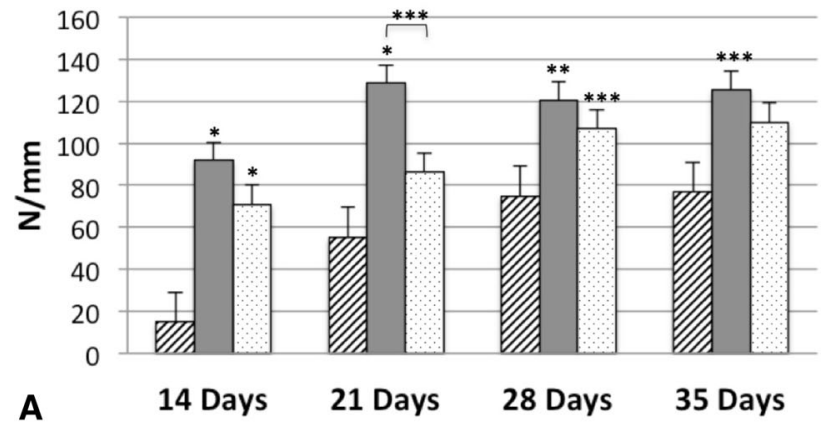

Ultimate Displacement

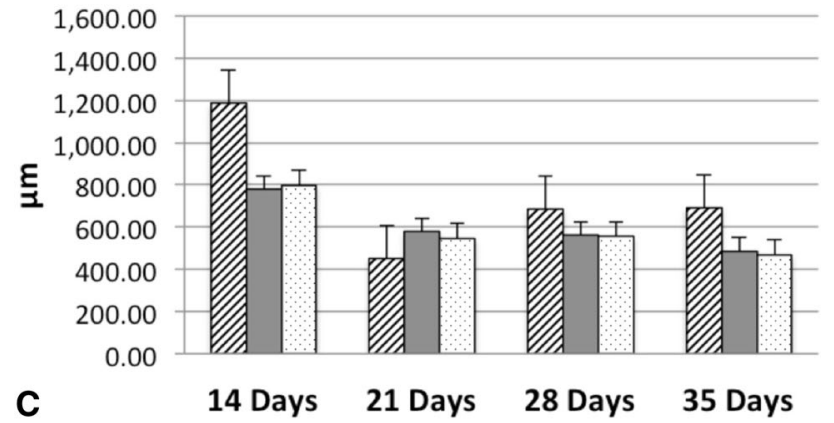

Ultimate Force
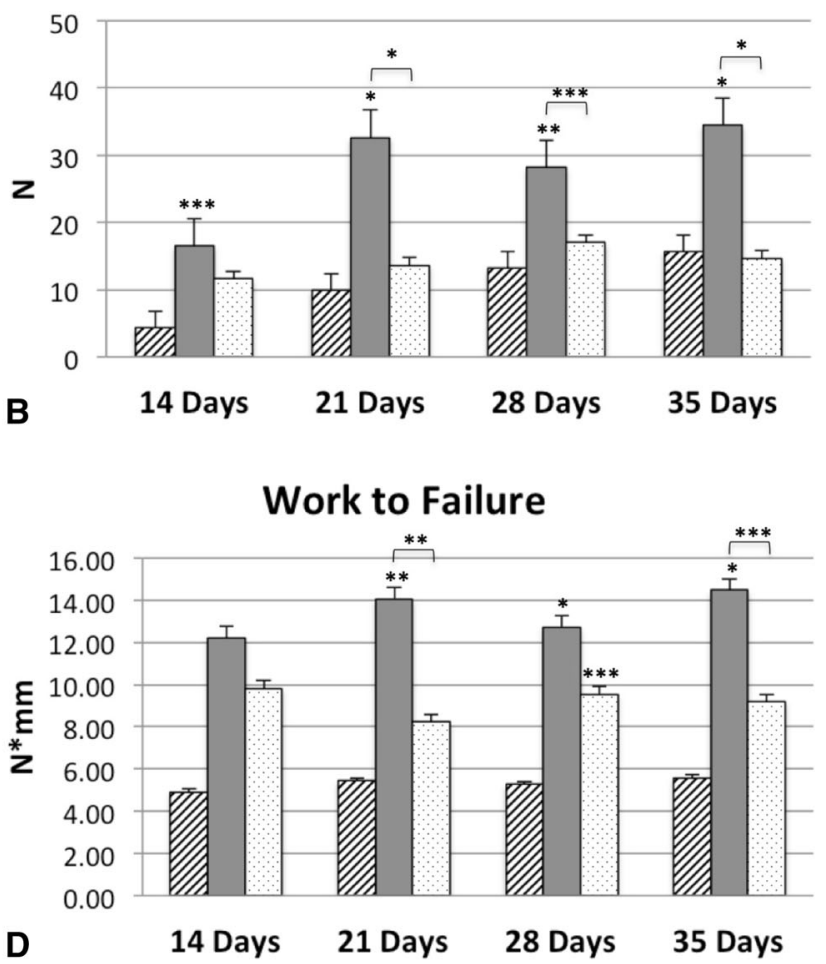

Fig. 2A-D (A) Stiffness, (B) ultimate force to failure, (C) ultimate displacement, and (D) work to failure results are shown. Data are presented as mean, standard error and $\mathrm{p}$ value $(* \mathrm{p}<0.001, * * \mathrm{p}<0.01, * * * \mathrm{p}<0.05)$.

mice had increased callus volume and improved radiographic healing time compared with wild type mice, especially during the early stages of healing (up to 14 days postfracture). We found similar results; the SOST KO group showed increased BV/TV and improved structural model index on $\mu \mathrm{CT}$ compared with the saline group (Fig. 1). Sclerostin depletion also can be achieved through systemic administration of Scl-Ab. In a mouse femoral osteotomy model, Cui et al. [6] reported increased BV/TV formation on $\mu \mathrm{CT}$ in the Scl-Ab-treated group compared with the saline group. According to their results these findings were more evident 4 weeks postfracture. Our study also showed increased BV/TV on $\mu \mathrm{CT}$ in the Scl-Abtreated group compared with saline group. In addition, the $\mu \mathrm{CT}$ results showed that the structural model index was improved in the antibody-treated group throughout all times in comparison to the saline group (Fig. 1D).

Biomechanically, Li et al. [14] showed increased strength of fracture healing callus in the SOST KO mice compared with wild type mice, especially during the early stages of healing (up to 14 days postfracture). We found that stiffness and ultimate force to failure were improved in the SOST KO group (Fig. 2). Concerning the sclerostin antibody, Cui et al. [6] reported increased force of load to failure on biomechanical testing in their Scl-Ab-treated group compared with the control group in a mouse femoral osteotomy model. We found increased stiffness on biomechanical testing of the Scl-Ab-treated group compared with the saline group (Fig. 2).

The results indicate that during the early stages of the healing process (14-21 days), radiographic and mechanical outcomes of the Scl-Ab and SOST KO groups were not different, with the numbers available. However, toward the end of the healing stages, the SOST KO group showed increased and ongoing bone formation in addition to stronger callus formation. Although the $\mathrm{Scl}-\mathrm{Ab}$ group plateaued and bone formation was less than expected, it still remained superior to that of the saline group. We hypothesize that this may be attributed to saturation of the sclerostin receptors, thus rendering them unresponsive to the inhibitory effect of the antibody or because the bone formation in the sclerostin antibody group had completed the callus formation phase and commenced bone remodeling in a more physiologic manner than the knockout group counterpart.

Systemic administration of sclerostin antibody enhanced bone formation and accelerated the healing process of fractures, which was not different, with the numbers 
available, from results achieved with complete depletion of the sclerostin gene, especially during the early stages of the healing process. Our study, and others [16, 22], highlight this method of enhancing bone formation as a promising method in the acute fracture model; we believe that sclerostin also deserves inquiry in additional animal studies as a possible approach for management of delayed unions of fractures. In addition, more research is required to assess adequate dosage, proper time of administration during fracture healing, and possible complications of this antibody.

Acknowledgments We thank Sami Abdullah BSc (Clinical Biomedical Laboratory, Shriner's Hospital for Children, Montreal, Quebec, Canada) for assistance with the logistics and with this study.

\section{References}

1. Axelrad TW, Kakar S, Einhorn TA, New technologies for the enhancement of skeletal repair. Injury. 2007;38(suppl 1):S49-62.

2. Beighton P. Sclerosteosis. J Med Genet. 1988;25:200-203.

3. Bonnarens F, Einhorn TA, Production of a standard closed fracture in laboratory animal bone. J Orthop Res. 1984;2:97-101.

4. Chen Y, Whetstone HC, Lin AC, Nadesan P, Wei Q, Poon R, Alman BA. Beta-catenin signaling plays a disparate role in different phases of fracture repair: implications for therapy to improve bone healing. PLoS Med. 2007;4:e249.

5. Colburn NT, Zaal KJ, Wang F, Tuan RS. A role for gamma/delta $\mathrm{T}$ cells in a mouse model of fracture healing. Arthritis Rheum, 2009;60:1694-1703.

6. Cui L, Cheng H, Song C, Li C, Simonet WS, Ke HZ, Li G. Timedependent effects of sclerostin antibody on a mouse fracture healing model. J Musculoskelet Neuronal Interact. 2013;13:178184.

7. French DM, Kaul RJ, D'Souza AL, Crowley CW, Bao M, Frantz GD, Filvaroff EH, Desnoyers L. WISP-1 is an osteoblastic regulator expressed during skeletal development and fracture repair. Am J Pathol. 2004;165:855-867.

8. Gamie Z, Korres N, Leonidou A, Gray AC, Tsiridis E. Sclerostin monoclonal antibodies on bone metabolism and fracture healing. Expert Opin Investig Drugs. 2012;21:1523-1534.

9. Garrison KR, Donell S, Ryder J, Shemilt I, Mugford M, Harvey I, Song F. Clinical effectiveness and cost-effectiveness of bone morphogenetic proteins in the non-healing of fractures and spinal fusion: a systematic review. Health Technol Assess. 2007;11:1150, iii-iv.

10. Govender S, Csimma C, Genant HK, Valentin-Opran A, Amit Y, Arbel R, Aro H, Atar D, Bishay M, Borner MG, Chiron P, Choong P, Cinats J, Courtenay B, Feibel R, Geulette B, Gravel C, Haas N, Raschke M, Hammacher E, van der Velde D, Hardy P, Holt M, Josten C, Ketterl RL, Lindeque B, Lob G, Mathevon H, McCoy G, Marsh D, Miller R, Munting E, Oevre S, Nordsletten L, Patel A, Pohl A, Rennie W, Reynders P, Rommens PM, Rondia J, Rossouw WC, Daneel PJ, Ruff S, Ruter A, Santavirta S, Schildhauer TA, Gekle C, Schnettler R, Segal D, Seiler H, Snowdowne RB, Stapert J, Taglang G, Verdonk R, Vogels L, Weckbach A, Wentzensen A, Wisniewski T; BMP-2 Evaluation in Surgery for Tibial Trauma (BESTT) Study Group. Recombinant human bone morphogenetic protein-2 for treatment of open tibial fractures: a prospective, controlled, randomized study of four hundred and fifty patients. $J$ Bone Joint Surg Am. 2002;84:2123-2134

11. Jho EH, Zhang T, Domon C, Joo CK, Freund JN, Costantini F, Wnt/beta-catenin/Tcf signaling induces the transcription of Axin2, a negative regulator of the signaling pathway. Mol Cell Biol. 2002;22: 1172-1183.

12. Junker U, Kneissel M. Combination for the treatment of bone loss. 2010, Google Patent WO2010115932 A1. Available at: https://www.google.com/patents/WO2010115932A1?cl=en. Accessed November 9, 2015.

13. Kramer I, Loots GG, A. Studer A, Keller H, Kneissel M. Parathyroid hormone (PTH)-induced bone gain is blunted in SOST overexpressing and deficient mice. J Bone Miner Res. 2010;25:178-189.

14. Li C, Ominsky MS, Tan HL, Barrero M, Niu QT, Asuncion FJ, Lee E, Liu M, Simonet WS, Paszty C, Ke HZ. Increased callus mass and enhanced strength during fracture healing in mice lacking the sclerostin gene. Bone. 2011;49:1178-1185.

15. Li X, Ominsky MS, Niu QT, Sun N, Daugherty B, D'Agostin D, Kurahara C, Gao Y, Cao J, Gong J, Asuncion F, Barrero M, Warmington K, Dwyer D, Stolina M, Morony S, Sarosi I, Kostenuik PJ, Lacey DL, Simonet WS, Ke HZ, Paszty C. Targeted deletion of the sclerostin gene in mice results in increased bone formation and bone strength. J Bone Miner Res. 2008;23:860869.

16. Li X, Ominsky MS, Warmington KS, Morony S, Gong J, Cao J, Gao Y, Shalhoub V, Tipton B, Haldankar R, Chen Q, Winters A, Boone T, Geng Z, Niu QT, Ke HZ, Kostenuik PJ, Simonet WS, Lacey DL, Paszty C. Sclerostin antibody treatment increases bone formation, bone mass, and bone strength in a rat model of postmenopausal osteoporosis. J Bone Miner Res. 2009;24:578-588.

17. Makhdom AM, Hamdy RC. The role of growth factors on acceleration of bone regeneration during distraction osteogenesis. Tissue Eng Part B Rev. 2013;19:442-453.

18. Makhdom AM, Rauch F, Lauzier D, Hamdy RC. The effect of systemic administration of sclerostin antibody in a mouse model of distraction osteogenesis. J Musculoskelet Neuronal Interact. 2014; $14: 124-130$.

19. Marsh D. Concepts of fracture union, delayed union, and nonunion. Clin Orthop Relat Res. 1998;355(suppl):S22-30.

20. Morse A, McDonald M, Kelly N, Melville K, Schindeler A, Kramer I, Kneissel M, van der Meulen M, Little D. Mechanical load increases in bone formation via a dclerostin-independent pathway. J Bone Miner Res. 2014;29:2456-2467.

21. Morse A, Yu NY, Peacock L, Mikulec K, Kramer I, Kneissel M, McDonald MM, Little DG. Endochondral fracture healing with external fixation in the Sost knockout mouse results in earlier fibrocartilage callus removal and increased bone volume fraction and strength. Bone. 2015;71:155-163.

22. Ominsky MS, Li C, Li X, Tan HL, Lee E, Barrero M, Asuncion FJ, Dwyer D, Han CY, Vlasseros F, Samadfam R, Jolette J, Smith SY, Stolina M, Lacey DL, Simonet WS, Paszty C, Li G, Ke HZ. Inhibition of sclerostin by monoclonal antibody enhances bone healing and improves bone density and strength of nonfractured bones. J Bone Miner Res. 2011;26:1012-1021.

23. Phieffer LS, Goulet JA. Delayed unions of the tibia. J Bone Joint Surg Am. 2006;88:206-216.

24. Poynton AR, Lane JM. Safety profile for the clinical use of bone morphogenetic proteins in the spine. Spine (Phila Pa 1976). 2002;27(16 suppl 1):S40-48.

25. Sarahrudi K, Thomas A, Albrecht C, Aharinejad S. Strongly enhanced levels of sclerostin during human fracture healing. $J$ Orthop Res. 2012;30:1549-1555.

26. ten Dijke P, Krause C, de Gorter DJ, Lowik CW, van Bezooijen RL. Osteocyte-derived sclerostin inhibits bone formation: its role 
in bone morphogenetic protein and Wnt signaling. $J$ Bone Joint Surg Am. 2008;90(suppl 1):31-35.

27. U.S. Department of Health and Human Services. The Guide for the Care and Use of Laboratory Animals. (NIH Publication No. 85-23). Bethesda, MD: National Institutes of Health; 1985.
28. Winkler DG, Sutherland MK, Geoghegan JC, Yu C, Hayes T, Skonier JE, Shpektor D, Jonas M, Kovacevich BE, StaehlingHampton K, Appleby M, Brunkow ME, Latham JA. Osteocyte control of bone formation via sclerostin, a novel BMP antagonist. EMBO J. 2003;22:6267-6276. 